\title{
FAKTOR - FAKTOR YANG MEMPENGARUHI KEPUTUSAN KONSUMEN DALAM PEMBELIAN SAYURAN ORGANIK DI KOTA SALATIGA
}

(Factors That Influence Costumer Dicisions In Purchasing Organic Vegetables In Salatiga)

\author{
Putri Kurniasih', Tinjung Mary Prihtanti ${ }^{2}$ \\ Agribisnis, Fakultas Pertanian dan Bisnis \\ Universitas Kristen Satya Wacana \\ email: kurniasihputri0@gmail.com ${ }^{1}$,tinjung.murjono@gmail.com²
}

Article Submitted : 01-08-2019

Article Accepted : 04-10-2019

\begin{abstract}
Organic vegetables are plants form leaves, legumes or grains are produced organically and certified by an official certification body. The study was conducted in Salatiga on month from April to May 2019. The sampling technique used in this research is Non-Probability Sampling with technique accidental. The number of samples taken 65 samples consisting of 35 samples of domestic consumers who decide to buy organic vegetables and 30 samples of households who decide to buy non-organic vegetables. The analysis technique used is by using logistic regression analysis. The result of this study state that age variables (X1) and family income variables (X2) have no significant effect on the dependent varible $(\mathrm{Y})$ purchasing decisions of organic vegetables. While for education level variables (X3), vegetable prices (X4), location of purchase (X5), vegetable quality (X6) and bandwagon effect (X7) significant effect on purchasing decisions for organic vegetables.
\end{abstract}

Keywords : purchase, organic vegetable, logistic regression.

\section{PENDAHULUAN}

Produk pertanian organik pada era sekarang, sangat menarik bagi petani maupun konsumen dikarenakan tidak adanya penggunaan bahan kimia sintesis yang dapat menimbulkan bahaya bagi kesehatan tubuh manusia dan lingkungan. Kesadaran akan pola hidup sehat membuat meningkatnya permintaan terhadap produk organik bagi sebagian besar konsumen. Hal ini menjadikan para petani mulai merubah sistem pola cocok tanam yang tidak menggunakan bahan kimia menjadi sistem pola cocok tanam pertanian organik (Lesmana dan Hidayat 2008). Saat ini kesadaran masyarakat akan gaya hidup sehat mulai meningkat terutama pada masyarakat kota. Menurut SPOI (Statistik Pertanian Organik Indonesia) tingkat pertumbuhan konsumsi sayuran organik di Indonesia dari tahun 2008 hingga tahun 2012 adalah sebesar 4,66\%. Pergeseran konsumsi dari sayuran non organik ke sayuran organik meningkat setiap tahunya.

Meskipun kesadaran masyarakat akan pentingnya menjaga kesehatan meningkat, namun tidak semua masyarakat beralih mengkonsumsi sayuran organik, perkembangan konsumsi sayuran organik masih terbatas dan biasanya dilakukan oleh lapisan masyarakat tertentu saja yang mengetahui manfaat sayuran organik. Kendala yang sering dihadapi konsumen dalam mengkonsumsi sayuran organik adalah harga sayuran organik yang lebih mahal dan tempat penjualan yang masih terbatas, biasanya hanya tersedia di tempat - tempat tertentu sehingga sulit terjangkau oleh 
seluruh lapisan masyarakat. Dari beberapa penelitian terdahulu menunjukkan faktor faktor yang mempengaruhi keputusan pembelian sayuran organik yaitu usia, jumlah pendapatan keluarga, tingkat pendidikan, harga sayuran, lokasi pembelian, dan kualitas. (Anggiasari, 2016).

Pada dasarnya, sebagian masyarakat dilokasi kota Salatiga telah mengkonsumsi sayuran organik. Namun tidak semua masyarakat Kota Salatiga mengetahui manfaat sayuran organik, sehingga sebagian besar masyarakat masih mengkonsumsi sayuran non organik. Berdasarkan latar belakang yang telah dipaparkan, maka peneliti tertarik untuk melakukan penelitian terhadap masalah tersebut dengan judul faktor - faktor yang mempengaruhi keputusan konsumen dalam pembelian sayuran organik di Kota Salatiga. Berdasarkan latar belakang di atas, maka dapat dirumuskan permasalahan yang dihadapi, yaitu bagaimana pengaruh karakteristik sosial ekonomi konsumen, antara lain: umur, pendapatan keluarga, tingkat pendidikan, harga sayuran, lokasi pembelian, kualitas sayuran, dan efek bandwagon dengan keputusan konsumen dalam pembelian sayuran organik di Kota Salatiga. Berdasarkan uraian diatas maka tujuan dari penelitian secara umum adalah untuk mengetahui faktor - faktor yang mempengaruhi keputusan dalam pembelian sayuran organik di Kota Salatiga.

\section{METODE PENELITIAN}

Penelitian ini dilaksanakan di Niki Baru, Go Organik, dan Tukang Sayoer yang $\operatorname{Ln}\left(\frac{p}{1-p}\right)=\mathrm{b}_{0}+\mathrm{b}_{1} \mathrm{X}_{1}+\mathrm{b}_{2} \mathrm{X}_{2}+\mathrm{b}_{3} \mathrm{X}_{3}+\mathrm{b}_{4} \mathrm{X}_{4}+\mathrm{b}_{5} \mathrm{X}_{5}+\mathrm{b}_{6} \mathrm{X}_{6}+\mathrm{b}_{7} \mathrm{X}_{7}+\varepsilon$

$\mathrm{H}_{0}$ : Tidak ada pengaruh antara variabel independen dengan variabel dependen terhadap keputusan konsumen dalam pembelian sayuran organik

$\mathrm{H \alpha}$ : Ada pengaruh antara variabel independen dengan variabel dependen terhadap keputusan konsumen dalam pembelian sayuran organik. dependen. ada di Salatiga pada bulan April - Mei 2019. Pemilihan lokasi penelitian dipilih secara sengaja (purposive). Jenis penelitian ini adalah penelitian deskriptif dengan menggunakan pendekatan kuantitatif. Menurut Azwar (2011) penelitian deskriptif hanya menganalisis pada taraf deskripsi yang menyajikan fakta secara sistematis agar mudah dipahami dan mudah dalam mengambil kesimpulan. Teknik pengambilan sampel yang digunakan pada penelitian ini yaitu Non Probability Sampling dengan teknik accidental. Non Probability Sampling adalah teknik penentuan sampel yang tidak memberikan peluang yang sama terhadap setiap anggota populasi untuk dipilih sebagai sampel (Sugiyono, 2014). Teknik accidental merupakan teknik penentu sampel berdasarkan kebetulan, yaitu konsumen yang secara kebetulan bertemu dengan peneliti dapat digunakan sebagai sampel, bila dipandang orang yang kebetulan ditemui itu cocok sebagai sumber data (Sugiyono 2009:85). Jumlah sampel yang akan diteliti yaitu sebanyak 65 sampel yang dianalisis terdiri dari 35 sampel rumah tangga konsumen yang membeli sayuran organik dan 30 sampel rumah tangga yang membeli sayuran non organik.

Menganalisis pengaruh faktor karakteristik sosial ekonomi terhadap keputusan pembelian sayuran organik dan kemampuan menaksir probabilitas individu untuk membeli sayuran organik digunakan rumus regresi logistik ganda menurut Sugiarto dan Harijono (2000) adalah:

Model regresi ganda logistik:

a. Saat nilai signifikansi $<0,05$ maka hipotesis dapat diterima (koefisien regresi signifikan). Hal ini menunjukkan bahwa variabel independen mempunyai pengaruh yang signifikan terhadap variabel

b. Saat nilai signifikansi $\geq 0,05$ maka hipotesis ditolak (koefisien regresi tidak 
signifikan). Hal ini menunjukkan bahwa variabel independen tidak mempunyai pengaruh yang signifikan terhadap variabel dependen.

Uji yang digunakan untuk mengetahui pengaruh dari variabel independen secara keseluruhan dan secara individu yaitu dengan menggunakan uji signifikansi sebagai berikut :

1. Uji Signifikansi secara Keseluruhan Nilai $G$ pada uji $G$ dengan formulasi sebagai berikut :

$$
\mathrm{G}=-2 \ln \left(\frac{\text { likehood }(\text { Model } B)}{\text { likehood }(\text { Model } A)}\right)
$$

Kriteria pengambilan keputusan yaitu:

a. H0 ditolak ketika $\mathrm{G}>$ model dengan variabel bebas signifikan pada tingkat signifikansi 5\%.

HASIL DAN PEMBAHASAN

\section{Karakteristik Konsumen Sayuran Organik}

b. H0 diterima ketika $\mathrm{G}<$ model dengan variabel bebas tidak signifikan pada tingkat signifikansi 5\%.

2. Uji Signifikansi secara Individual

Nilai Wald pada uji W (wald) diperoleh dengan menggunakan rumus :

$$
W i=\left(\frac{\beta_{1}}{S e_{1} \beta}\right)^{2}
$$

Kriteria Pengambilan Keputusan yaitu :

a. Jika $W i<0,05$, maka variabel bebas secara individu berpengaruh nyata terhadap keputusan konsumen dalam pembelian sayuan organik.

b. Jika $W i>0,05$, maka variabel independen secara individu tidak berpengaruh nyata terhadap keputusan konsumen dalam pembelia sayuran organik.

Karakteristik responden bertujuan untuk mengetahui gambaran sampel penelitian meliputi jenis kelamin, status perkawinan, tingkat pendidikan, usia, dan pendapatan keluarga.

Tabel 1. Karakteristik Responden

\begin{tabular}{lcccc}
\hline \multicolumn{1}{c}{ Karakteristik } & \multicolumn{2}{c}{ Non Organik } & \multicolumn{2}{c}{ Organik } \\
& Frekuensi & Persentase & Frekuensi & Persentase \\
\hline Jenis Kelamin & 4 & & & \\
Laki-laki & 26 & 13,3 & 26 & 25,7 \\
Perempuan & 30 & 86,7 & 35 & 100,0 \\
\hline Total & & 100,0 & & \\
\hline Status Perkawinan & 3 & & 2 & 5,7 \\
Belum Menikah & 27 & 10,0 & 33 & 94,3 \\
Menikah & 30 & 100,0 & 35 & 100,0 \\
\hline Total & & & & \\
\hline Tingkat Pendidikan & 11 & 36,7 & 0 & 0,0 \\
SD & 6 & 20,0 & 0 & 0,0 \\
SMP & 9 & 30,0 & 7 & 20,0 \\
SMA & 4 & 13,3 & 28 & 80,0 \\
S1 & 30 & 100,0 & 35 & 100,0 \\
\hline Total & & & & \\
\hline Umur (tahun) & 2 & 6,7 & 12 & 34,3 \\
20-29 & 10 & 33,3 & 14 & 40,0 \\
$30-39$ & 8 & 26,7 & 8 & 22,3 \\
$40-49$ & 7 & 23,3 & 1 & 3,4 \\
\hline $0-59$ & & & & \\
\hline
\end{tabular}




\begin{tabular}{lcccc}
\hline \multirow{2}{*}{ Karakteristik } & \multicolumn{2}{c}{ Non Organik } & \multicolumn{2}{c}{ Organik } \\
& Frekuensi & Persentase & Frekuensi & Persentase \\
\hline $60-69$ & 2 & 6,7 & 0 & 0 \\
$70-79$ & 1 & 3,3 & 0 & 0 \\
\hline Total & 30 & 100,0 & 35 & 100,0 \\
\hline Pendapatan Keluarga & & & & \\
(Rp/Bulan) & 15 & 50,0 & 6 & 17,1 \\
Rp 1.000.000-Rp 2.500.000 & 6 & 20,0 & 13 & 37,1 \\
Rp 2.600.000-Rp 4.100.000 & 6 & 20,0 & 8 & 22,9 \\
Rp 4.200.000-Rp 5.700.000 & 2 & 6,7 & 2 & 5,7 \\
Rp 5.800.000-Rp 7.300.000 & 1 & 3,3 & 2 & 5,7 \\
Rp 7.400.000-Rp 8.900.000 & & & & \\
Rp 9.000.000-Rp & 0 & 0 & 4 & 11,5 \\
10.000.000 & 30 & 100,0 & 35 & 100,0 \\
\hline Total & & & & \\
\hline
\end{tabular}

Sumber : Data Primer Olah

Berdasarkan jenis kelamin yang diperoleh pada umumnya responden yang membeli sayuran non organik maupun sayuran organik adalah perempuan. Hal ini dikarenakan pada umumnya ibu rumah tangga lebih mengetahui kebutuhan dapur dan sering berbelanja ke pasar lebih jika dibandingkan dengan laki-laki. Berdasarkan status perkawinan pada umumnya responden dalam penelitian ini yang membeli sayuran non organik maupun sayuran organik pada umumnya sudah menikah. Pada lama pendidikan diperoleh pada umumnya pembeli sayur non organik memiliki lama pendidikan 6 tahun atau tingkat SD yaitu sebanyak $36,7 \%$. Pada pembeli sayur organik pada umumnya pada tingkat pendidikan sarjana atau lama pendidikan 16 tahun sebanyak $80,0 \%$. Hal ini menggambarkan bahwa pada umumnya konsumen sayuran organik memiliki konsumen dengan tingkat pendidikan yang lebih tinggi dibandingkan dengan tingkat pendidikan konsumen sayuran non organik.

\section{Perilaku Pembelian Sayuran}

Tabel 2. Frekuensi Harga, Jumlah, Jarak Pembelian Sayuran

\begin{tabular}{|c|c|c|c|c|}
\hline \multirow{2}{*}{ Frekuensi } & \multicolumn{2}{|c|}{ Non Organik } & \multicolumn{2}{|c|}{ Organik } \\
\hline & Jumlah & Persentase & Jumlah & Persentase \\
\hline \multicolumn{5}{|c|}{ Pembelian sayuran dalam sebulan } \\
\hline 3 Kali & 0 & 0,0 & 2 & 5,7 \\
\hline 5 Kali & 3 & 10,0 & 4 & 11,4 \\
\hline 7 Kali & 5 & 16,7 & 8 & 22,9 \\
\hline Setiap Hari & 22 & 73,3 & 21 & 60,0 \\
\hline Total & 30 & 100,0 & 35 & 100,0 \\
\hline \multicolumn{5}{|c|}{$\begin{array}{l}\text { Jumlah sayuran yang dibeli } \\
\text { (kg/pembelian) }\end{array}$} \\
\hline $0,12-1,42$ & 30 & 100,0 & 31 & 88,6 \\
\hline $1,42-2,72$ & 0 & 0,0 & 2 & 5,7 \\
\hline $2,72-4,00$ & 0 & 0,0 & 2 & 5,7 \\
\hline Total & 30 & 100,0 & 35 & 100,0 \\
\hline
\end{tabular}




\begin{tabular}{lrrrc}
\hline \multicolumn{2}{c}{ Frekuensi } & \multicolumn{2}{c}{ Non Organik } & \multicolumn{2}{c}{ Organik } \\
& Jumlah & Persentase & Jumlah & Persentase \\
\hline Jarak $(\mathrm{km})$ & 30 & 100,0 & 31 & \\
$0,20-8,20$ & 0 & 0,0 & 2 & 88,6 \\
$8,20-16,20$ & 0 & 0,0 & 2 & 5,7 \\
$16,20-24,20$ & 30 & 100,0 & 35 & 5,7 \\
\hline Total & & & & 100,0 \\
\hline
\end{tabular}

Pada frekuensi pembelian sayuran dalam sebulan baik konsumen pembeli sayuran non organik maupun konsumen yang membeli sayuran organik pada umumnya melakukan pembelian setiap hari dengan masing-masing sebanyak $73,3 \%$ dan $60,0 \%$.

Faktor - Faktor Yang Mempengaruhi Keputusan Konsumen dalam Pembelian Sayuran Organik

Analisis yang digunakan untuk mengetahui faktor - faktor yang mempengaruhi keputusan konsumen dalam pembelian sayuran organik di Kota Salatiga yaitu dengan menggunakan analisis regresi logistik. Ada tujuh faktor yang diduga berpengaruh secara signifikan terhadap keputusan konsumen dalam pembelian sayuran organik. Faktor - faktor yang diduga mempengaruhi keputusan konsumen dalam pembelian sayuran organik adalah 1). Umur, 2). Pendapatan Keluarga, 3). Tingkat Pendidikan, 4). Harga sayuran, 5). Lokasi pembelian, 6). Kualitas sayuran, dan 7). Efek bandwagon.
Faktor - faktor yang diduga signifikan diidentifikasi dengan melihat nilai signifikansi pengaruh variabel bebas secara bersama - sama dan secara individu terhadap variabel terikat. Pengujian terhadap pengaruh tujuh variabel bebas dilakukan dengan melihat nilai signifikansi pada chi-square yang dihitung dari hasil uji Omnibus Tests of Model Coefficients, jika signifikansi chisquare $<5 \%$ maka tujuh variabel bebas secara signifikan dapat berpengaruh terhadap peluang konsumen pembeli sayuran organik, dari hasil tersebut dapat menunjukkan goodness of fit dari model yang disusun. Variabel bebas secara individu pada penelitian ini dapat dikatakan berpengaruh signifikan apabila nilai signifikansi $<5 \%$, hal ini dapat diketahui dari nilai signifikansi Uji Wald. Dalam hasil analisis regresi logistik pada Tabel. 3 berikut ini menunjukkan adanya pengaruh variabel bebas secara bersama sama.

Tabel. 3 Hasil Analisis Regresi untuk Goodness of Fit Model secara Keseluruhan

\begin{tabular}{llll}
\hline \multicolumn{1}{c}{ Uji } & & Hasil & \multicolumn{1}{c}{ Keterangan } \\
\hline Omnibus Tests of & Chi-square & Signifikansi & Berpengaruh signifikan \\
Model Coefficients & 75,888 & $0,01 \%$ & \\
\hline Model Summary & Cox \& Snell R & Nagelkerke $R$ & Berpengaruh signifikan \\
& Square & Square & \\
& $68,9 \%$ & $92 \%$ & \\
\hline Hosmer and & Chi-Square & Signifikansi & Model Fit \\
Lemeshow Test & 49,5 & $9,9 \%$ & \\
\hline
\end{tabular}

Berdasarkan hasil analisis regresi logistik yang terdapat pada Tabel.3 diketahui bahwa secara menyeluruhan, model regresi logistik yang didapatkan dari analisis bisa digunakan untuk memprediksi peluang konsumen pembeli sayuran organik. Kesimpulan ini didapat melalui hasil analisis regresi logistik meliputi beberapa kriteria 
yang harus dipenuhi oleh hasil analisis regresi logistik agar model dapat digunakan lebih lanjut. Kriteria tersebut yaitu, antara lain : Overall Test (Omnibus Test of Model
Coefficients), Model Sumarry, dan Hosmer and Lameshow.

1. Overall Test Model Logit Mengenai Keputusan Konsumen dalam Pembelian Sayuran Organik

Tabel 4. Omnibus Test of Model Coefficients Model Logit

\begin{tabular}{cccc}
\hline & Chi Square Test Omnibus & Signifikansi & Keterangan \\
\hline Step & 75,888 & 0,000 & Model Fit \\
Block & 75,888 & 0,000 & Model Fit \\
Model & 75,888 & 0,000 & Model Fit \\
\hline
\end{tabular}

Sumber : Data Primer Olah

Berdasarkan Tabel 4 tersebut, hasil chisquare menunjukkan nilai sebesar 75,888 dengan signifikansi sebesar $0,01 \%$. Nilai pada Chi-square tersebut kurang dari 5\%, menunjukkan bahwa dengan tingkat kepercayaan 95\% secara bersamaan maka variabel bebas yang dianalisis dapat berpengaruh secara signifikan terhadap peluang konsumen dalam pembelian sayuran

Tabel 5. Nagelkerke R Square Model Logit

\begin{tabular}{lll}
\hline Cox \& Snell R Square & Nagelkerke R Square & Keterangan \\
\hline 0,689 & 0,920 & Signifikan \\
\hline
\end{tabular}

Sumber : Data Primer Olah

Berdasarkan pada Tabel 5 tersebut, Nilai Nagelkerke $R$ Square menunjukkan hasil yang lebih besar dari 50\% yang artinya variabel bebas bisa menjelaskan variabilitas keputusan konsumen dalam pembelian sayuran organik. Pada hasil Cox \& Snell $R$ Square menunjukkan nilai sebesar 68,9\% sedangkan Nagelkerke $R$ Square sebesar $92 \%$. Nilai pada Nagelkerke $R$ Square lebih besar dibandingkan dengan nilai Cox \& Snell $R$ Square, yang artinya variabilitas pada organik. Dari hasil tersebut bisa disimpulkan bahwa model dapat digunakan untuk analisis lebih lanjut ketika ditemukan minimal satu variabel bebas yang berpengaruh pada variabel tidak bebas.

2. Nagelkerke $R$ Square dari Model Logit Mengenai Keputusan Konsumen dalam Pembelian Sayuran Organik

Tabel 6. Hosmer and Lameshow Test dari Model Logit

\begin{tabular}{lll}
\hline Chi Square & Signifikansi & Keterangan \\
\hline 0,495 & 0,999 & Signifikan \\
\hline
\end{tabular}

Sumber : Data Primer Olah 
Dari hasil uji Hosmer and Lameshow Test menunjukkan nilai chi-square sebesar 0,495 dan nilai signifikansi sebesar 9,9\%. Signifikansi memiliki nilai sebesar 0,999 > 0,05 dengan taraf kepercayaan $95 \%$, dari hasil tersebut dapat disimpulkan bahwa model yang memiliki kecocokan dengan data atau model regresi dinilai fit artinya model regresi layak untuk digunakan dalam analisis lebih lanjut atau cukup mampu menjelaskan data dan sesuai dengan kondisi yang terjadi. Secara bersama - sama tujuh faktor yang diduga mempunyai pengaruh nyata terhadap keputusan konsumen dalam pembelian sayuran organik. Selanjutnya yaitu mengetahui pengaruh dan besaran pengaruh dari variabel bebas secara individu terhadap keputusan konsumen dalam pembelian sayuran organik. Nyata atau tidaknya pengaruh diidentifikasi dengan melihat nilai signifikansi dari uji wald masing - masing varibel bebas pada Tabel. 7. Pada output analisis regresi logistik. Selain nilai tersebut, model hasil analisis dan jenis pengaruh variabel baik yang berpengaruh berbanding lurus atau berbanding terbalik bisa diketahui dengan melihat nilai konstanta masing masing variabel bebas. Berikut adalah hasil analisisnya :

Tabel 7. Koefisien, Wald, dan Signifikansi

\begin{tabular}{|c|c|c|c|c|c|c|}
\hline Variabel & $\mathrm{B}$ & Std.Error & Wald & $\mathrm{P}$ & $\mathrm{OR} \pm 95 \%$ & Keputusan \\
\hline Konstan & $\begin{array}{l}- \\
80,925\end{array}$ & 49,356 & 2,688 & & & \\
\hline Umur & 1.654 & 4,202 & 0,155 & 0,694 & $\begin{array}{l}5,228 \\
(0,001 \pm 19736,083)\end{array}$ & $\begin{array}{l}\text { Tidak } \\
\text { Signifikan }\end{array}$ \\
\hline Pendapatan Keluarga & -0.597 & 1,674 & 0,127 & 0,721 & $\begin{array}{l}0,550 \\
(0,021 \pm 14,648)\end{array}$ & $\begin{array}{l}\text { Tidak } \\
\text { Signifikan }\end{array}$ \\
\hline Tingkat Pendidikan & 1.325 &, 623 & 4,517 & 0,034 & $\begin{array}{l}3,763 \\
(1,109 \pm 12,771)\end{array}$ & Signifikan** \\
\hline Harga Sayuran & 4.495 & 2,173 & 4,278 & 0,039 & $\begin{array}{l}89,556 \\
(1,265 \pm 6338,693)\end{array}$ & Signifikan** \\
\hline Lokasi Pembelian & -6.397 & 3,440 & 3,459 & 0,063 & $\begin{array}{l}0,002 \\
(0,001 \pm 1,410)\end{array}$ & Signifikan* \\
\hline Kualitas Sayuran & 7.586 & 3,702 & 4,200 & 0,040 & $\begin{array}{l}1970,428 \\
(1,392 \pm 2789337,589)\end{array}$ & Signifikan** \\
\hline Efek Bandwagon & 7.643 & 3,712 & 4,239 & 0,040 & $\begin{array}{l}2085,473 \\
(1,443 \pm 3013514,370)\end{array}$ & Signifikan** \\
\hline
\end{tabular}

Sumber : Data Primer Olah

Keterangan $=*($ signifikan pada $10 \%) ; *($ signifikan pada $5 \%)$

Variabel bebas yang mempunyai pengaruh nyata terhadap keputusan konsumen dalam pembelian sayuran organik adalah tingkat pendidikan, harga sayuran, lokasi pembelian, kualitas sayuran, dan efek bandwagon. Pada penelitian ini taraf nyata yang digunakan adalah $5 \%$ dan $10 \%$.
Variabel lain yaitu variabel umur dan pendapatan keluarga tidak berpengaruh secara nyata terhadap keputusan konsumen dalam pembelian sayuran organik. Pada Tabel. 8 dapat dilihat model dari analisis regresi logistik, dengan melihat nilai koefisiennya yaitu :

$$
\mathrm{Y}=\frac{\left.2,7183^{(-80,925+1,654 X 1-0,594 \times 2+1,325 x 3+4,495 x 4-6,397 \times 5} 7,586 \times 6+7,643 \times 7\right)}{\left.1-2,7183^{-80,925+1,654 X 1}, 594 \times 2+1,325 x 3+4,495 x 4 \quad, 397 \times 5+7,586 \times 6+7,643 \times 7\right)}
$$


Pengaruh pada masing - masing variabel bebas yang signifikan terhadap keputusan konsumen dalam pembelian sayuran organik di Kota Salatiga dapat dijelaskan secara terperinci sebagai berikut: 1. Umur (X1)

Berdasarkan hasil analisis regresi logistik variabel umur (X1) mempunyai nilai signifikansi sebesar 0,694 atau nilai error sebesar 69,4\%. Nilai ini menunjukkan bahwa pada taraf kepercayaan sebesar $95 \%$ variabel umur tidak berpengaruh nyata terhadap keputusan konsumen dalam pembelian sayuran organik di Kota Salatiga. Koefisien regresi yang diperoleh adalah 1,654 dan nilai ood ratio sebesar 2,199 yang dapat diartikan peluang konsumen untuk mengambil keputusan membeli sayuran organik sebesar 2,199 persen dibandingkan dengan keputusan pembelian sayuran non organik jika umur meningkat 1 persen.

\section{Pendapatan Keluarga (X2)}

Pendapatan keluarga adalah variabel yang menunjukkan banyaknya materi berupa uang yang dihasilkan dalam sebuah keluarga. Hasil analisis regresi logistik menunjukkan bahwa nilai pendapatan keluarga mempunyai nilai signifikansi sebesar 0,721 atau nilai error sebesar $72,1 \%$. Nilai ini menunjukkan bahwa pada taraf kepercayaan $95 \%$ variabel pendapatan keluarga tidak mempunyai pengaruh nyata terhadap keputusan konsumen dalam pembelian sayuran organik di Kota Salatiga. Koefisien regresi yang diperoleh adalah $-0,597$ dan nilai ood ratio sebesar 1,941 yang dapat diartikan peluang konsumen untuk mengambil keputusan membeli sayuran non organik sebesar 1,941 persen dibandingkan dengan keputusan membeli sayuran organik jika pendapatan meningkat 1 persen.

\section{Tingkat Pendidikan (X3)}

Tingkat pendidikan merupakan salah satu faktor yang diduga mempengaruhi keputusan konsumen dalam pembelian sayuran organik di Kota Salatiga. Berdasarkan hasil analisis regresi logistik variabel tingkat pendidikan (X3) mempunyai nilai signifikansi sebesar 0,034 atau nilai error sebesar 3,4\%. Nilai ini menunjukkan bahwa pada taraf kepercayaan $95 \%$ variabel tingkat pendidikan mempunyai pengaruh nyata terhadap keputusan konsumen dalam pembelian sayuran organik di Kota Salatiga. Koefisien regresi yang diperoleh adalah 1,325 dan nilai ood ratio sebesar yaitu 2,305 yang dapat diartikan peluang konsumen untuk mengambil keputusan membeli sayuran organik akan meningkat sebesar 2,305 kali. Dengan kata lain peluang konsumen pembeli sayuran organik adalah sebesar 2,305 kali lebih tinggi daripada pembeli sayuran non organik.

\section{Harga Sayuran (X4)}

Harga sayuran merupakan salah satu faktor yang diduga mempengaruhi keputusan konsumen dalam pembelian sayuran organik. Berdasarkan analisis regresi logistik variabel harga sayuran (X4) mempunyai nilai signifikansi sebesar 0,039 atau nilai error sebesar 3,9\%. Nilai ini menunjukkan bahwa pada taraf kepercayaan sebesar 95\% variabel harga sayuran mempengaruhi pengaruh nyata terhadap keputusan konsumen dalam pembelian sayuran organik di Kota Salatiga. Koefisien regresi yang diperoleh adalah 4,495 dan nilai ood ratio 11,010 yang dapat diartikan peluang konsumen untuk mengambil keputusan pembelian sayuran organik lebih tinggi 11,010 persen dibandingkan dengan keputusan pembelian sayuran non organik jika harga sayuran meningkat 1 persen.

\section{Lokasi Pembelian (X5)}

Lokasi pembelian diduga sebagai salah satu fakor yang mempengaruhi keputusan konsumen dalam pembelian sayuran organik. Berdasarkan analisis regresi logistik variabel lokasi pembelian (X5) mempunyai nilai signifikansi sebesar 0,063 atau nilai error sebesar 6,3\%. Hal ini menunjukkan bahwa pada taraf kepercayaan sebesar $90 \%$ varibel lokasi pembelian berpengaruh nyata terhadap keputusan pembelian sayuran organik di Kota Salatiga. Koefisien regresi yang diperoleh adalah $-6,397$ dan nilai ood ratio sebesar 
0,089. Koefisien regresi menunjukkan adanya pengaruh negatif, oleh karena itu dapat dikatakan bahwa lokasi pembelian yang cenderung tidak lebih jauh maka memiliki kemungkinan lebih besar untuk memiliki keputusan pembelian organik. Sedangkan peluang konsumen dalam membeli sayuran organik meningkat sebesar 0,089 kali. Dengan kata lain peluang konsumen dalam pembelian sayuran organik adalah sebesar 0,089 kali lebih tinggi daripada konsumen pembeli sayuran non organik.

\section{Kualitas Sayuran (X6)}

Kualitas sayuran merupakan salah satu faktor yang diduga mempengaruhi konsumen dalam pembelian sayuran organik. Berdasarkan analisis regresi logistik variabel kualitas sayuran (X6) mempunyai nilai signifikansi sebesar 0,040 atau nilai error sebesar 4\%. Nilai ini menunjukkan bahwa pada taraf kepercayaan $95 \%$ variabel kualitas sayuran mempunyai pengaruh nyata terhadap keputusan kosumen dalam membeli sayuran organik di Kota Salatiga. Nilai koefisien regresi yang diperoleh adalah 7,586 dan nilai ood ratio sebesar 1,497. Hal ini berarti peluang konsumen dalam pembelian sayuran organik akan meningkat sebesar 1,497kali. Dengan kata lain peluang konsumen dalam membeli sayuran organik lebih tinggi 1,497 persen dibandingkan dengan keputusan membeli sayuran non organik jika kualitas sayuran meningkat $1 \%$.

\section{Efek Bandwagon (X7)}

Efek bandwagon merupakan salah satu variabel yang diduga mempengaruhi keputusan konsumen dalam pembelian sayuran organik. Berdasarkan hasil analisis regresi logistik variabel efek bandwagon (X7) yang memiliki nilai signifikansi sebesar 0,040 atau nilai error sebesar 4\%. Nilai ini menunjukkan bahwa pada taraf kepercayaan 95\% variabel efek bandwagon berpengaruh nyata terhadap keputusan konsumen dalam pembelian sayuran organik di Kota Salatiga. Nilai koefisien regresi sebesar 7,643 dan ood ratio sebesar 5,850. Hal ini berarti peluang konsumen dalam pembelian sayuran organik akan meningkat sebesar 5,850 kali. Dengan kata lain peluang konsumen dalam membeli sayuran organik lebih tinggi 5,850\% jika dibandingkan dengan keputusan membeli sayuran non organik jika efek bandwagon meningkat $1 \%$.

\section{KESIMPULAN DAN SARAN}

\section{Kesimpulan}

Berdasarkan hasil penelitian mengenai keputusan konsumen dalam pembelian sayuran organik di Kota Salatiga, menunjukkan bahwa variabel umur (X1) dan variabel pendapatan keluarga (X2) tidak berpengaruh signifikan terhadap keputusan pembelian sayuran karena mempunyai nilai signifikansi lebih besar dari 0,05. Sedangkan variabel tingkat pendidikan (X3), varibel harga sayuran (X4), variabel lokasi pembelian (X5), variabel kualitas sayuran (X6), dan variabel efek bandwagon (X7) berpengaruh signifikansi terhadap keputusan pembelian sayuran organik di Kota Salatiga karena mempunyai nilai signifikan lebih kecil dari 0,05.

\section{Saran}

Berdasarkan hasil penelitian mengenai keputusan konsumen dalam pembelian sayuran organik di Kota Salatiga, dapat diberikan saran khususnya bagi peneliti selanjutnya dapat mengembangkan penelitian ini dengan menganalisis faktorfaktor lainnya yang diduga mempengaruhi keputusan pembelian.

\section{DAFTAR PUSTAKA}

Adriani, Yumira. 2017. Analisis Regresi Logistik Untuk Menentukan FaktorFaktor Yang Mempengaruhi Indeks Prestasi Kumulatif (IPK) Mahasiswa FMIPA Universitas Sam Ratulangi Manado. JdC, Vol. 6, No. 2.

Andilla Y. 2011. Analisis Sikap Konsumen dalam Membeli Sayuran Segar di Pasar Modern Bumi Serpong Damai 
(BSD) Tangerang Selatan. [Skripsi]. Fakultas Sains dan Teknologi, UIN Syarif Hidayatullah, Jakarta.

Anggiasari, Ni Made. 2016. Sikap dan Pengambilan Keputusan Pembelian Sayuran Organik oleh Konsumen di Kota Bandar Lampung. [Skripsi]. Fakultas Pertanian, Universitas Lampung, Banar Lampung.
Ghozali. I. Aplikasi Analisis Multivariate dengan Program SPSS. Edition 12. Semarang.

Lesmana, T dan A.S. Hidayat. 2008. National Study on Organic Agriculture. LIPI

Sugiarto dan Harijono, 2000. Peramalan Bisnis. Gramedia Pustaka, Jakarta.Universitas Diponegoro, 2007. 